\title{
Experimental and Numerical Investigation of the Effect of Different Temperature and Deformation Speeds on Mechanical Properties and Springback Behaviour in Al-Zn-Mg-Cu Alloy
}

\author{
Suleyman KILIC \\ Kırşehir Ahi Evran University, Department of Mechanical Engineering, 40100 Kırşehir, Turkey, \\ E-mail: suleymankilic@ahievran.edu.tr
}

crossref http://dx.doi.org/10.5755/j01.mech.25.5.22689

\section{Introduction}

Increasing oil prices and environmental pollution, as in all industries, also cause the automotive industry into research on the use of new materials. The $7 \mathrm{XXX}$ series aluminium alloy, which is frequently used in the aerospace industry, has been not yet widely used in the automotive industry. In spite of its low density, it is a material that attracts attention due to its high strength in the lightening process. The lightening process is planned and carried out on two main issues. The first is the use of a material with high strength in a thinner thickness. For example, when more strength DP490 steel is used instead of BH340 steel at the car door, about $7 \%$ weight gain is achieved (Fig. 1) [1]. The second one is to choose materials with low density. As shown in Fig. 2, a reduction of about $60 \%$ can be achieved if low-density aluminium is used instead of using steel in the B pillar section of the automobile [2]. In another study, it is stated that decreasing the density instead of increasing the strength will provide more lightening [3].
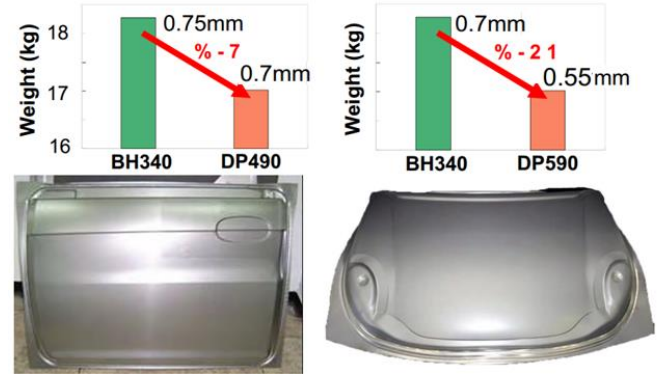

Fig. 1 Lightening with using high-strength steel [1]

It is seen that studies on the use of $7 \mathrm{XXX}$ series aluminium alloys have also increased in recent years about lightening process in the automotive industry. However, due to some problems in the aluminium alloy, it is more difficult to shape than steel. The formability of T6 at room temperature is weak and at high temperatures, it has been widely investigated [4-7]. Therefore, springback, deep drawing and FLD tests of the material are important.

Feister et al. [8] obtained FLC curves of 7075-T6 material at different temperatures and used it in finite element analysis. It is shown that the formability increases with increasing of the temperature. At the analysis programs are said to be needed to develop new models. In another study, deep drawing properties at different temperatures were examined experimentally and were compared with finite element analysis [9]. They showed that the simulation results were similar to the experimental results. In a different study, hot stamping was applied in 7075-T4 material of different aging temperatures and times [10]. It is understood that the dissolution temperature of $510^{\circ} \mathrm{C}$ is the most suitable temperature and the solution time does not have much effect. Formability at different temperatures and times of the 7075T6 material is investigated and it is shown that its formability increases at high temperatures [11]. It is said that the effect of the lubricant is very high in hot forming and that the 6061 series alloy is better than the alloy of 7075 series [12]. 5182 and 7075 aluminium alloys at different temperatures and speeds are compared with formability. 5182 has better hot formability than 7075 [13].

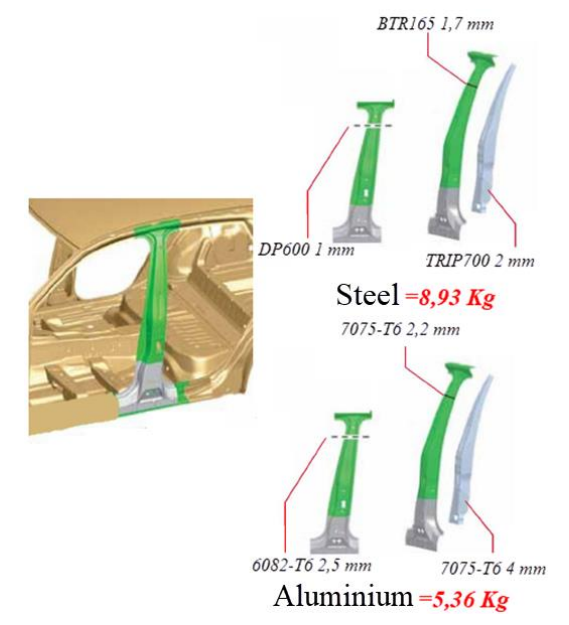

Fig. 27075 aluminium alloy in lightening studies [2]

The main problem of the sheet metal industry is springback behavior. In the literature, many studies have been done to minimize springback and to be estimated this. Because of its simplicity, $\mathrm{V}$ bending is generally preferred $[14,15]$.

7XXX series aluminium alloys can be applied to the aging process. Mechanical properties vary according to the aging parameters. T6 refers to the state that the material is most strength. Therefore, it is quite difficult to be formed. After painting in the automotive industry, paint baking is carried out at $100-200^{\circ} \mathrm{C}$ for $10-30$ minutes [16]. The aim of this study is to investigate the effect of paint baking process on aging. By taking to the solution, the softened part is shaped and then strength is increased with paint baking process. Fig. 3 shows the shaping and painting process of sheet metal material. In a study which was investigated the effect of paint baking process at the temperature of T6, samples were kept at $180^{\circ} \mathrm{C}$ for 20 minutes. This process decreases the tensile strength and increases ductility [5]. Argandoña et 
al. [17] also examined the formability of B pillars in the 7075-W alloy at room temperature.

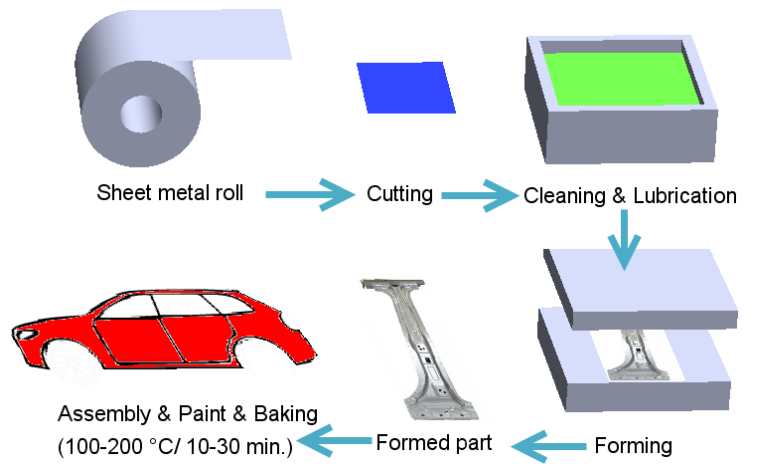

Fig. 3 Sheet metal forming and painting process in the automotive industry

In this study, the change of mechanical properties is investigated by making quenching process. In addition, the effect of springback and deformation speed is examined. The experimental data is modelled in the finite element analysis program and the results are compared. In the analysis, different yield criteria and hardening curve models are examined and their effects on the results are shown. The strength of the parts formed easily will be increased again with the paint baking process in the automotive industry.

\section{Material and method}

In this study, a 7075-T6 aluminium alloy in $2 \mathrm{~mm}$ thickness is used. T6 Samples are taken to the solution for 2 hours at $500^{\circ} \mathrm{C}$ and are quenched at room temperature. Then, bending and tensile tests are performed to samples in T6 and Quenching in 1, 25, 125, $500 \mathrm{~mm} / \mathrm{min}$ deformation rates and at $25,100^{\circ} \mathrm{C}$ temperatures. Tensile test specimens are prepared by cutting with water jet according to ASTM E8 standard (Fig. 4).

Table 1

Chemical composition of AA7075 (in wt. \%)

\begin{tabular}{|l|l|l|l|l|l|l|l|l|}
\hline $\mathrm{Si}$ & $\mathrm{Fe}$ & $\mathrm{Cu}$ & $\mathrm{Mn}$ & $\mathrm{Mg}$ & $\mathrm{Cr}$ & $\mathrm{Zn}$ & $\mathrm{Ti}$ & $\mathrm{Ti}+\mathrm{Zr}$ \\
\hline 0.07 & 0.12 & 1.5 & 0.02 & 2.6 & 0.18 & 5.8 & 0.05 & 0.08 \\
\hline
\end{tabular}

Shimadzu Autograph AGS-X $10 \mathrm{kN}$ device is used in tensile and bending tests. In Fig. 5 is shown the bending mold and dimensions. Each experiment is repeated at least three times and more. Strains are measured by using a video type extensometer.

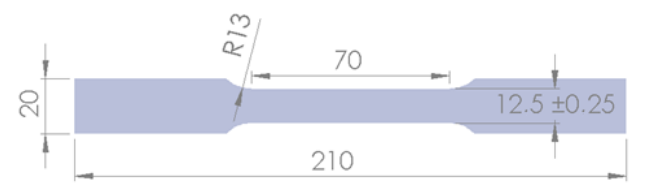

Fig. 4 The tensile test specimen dimensions (ASTM E8 Standard)

Erichsen model 134 is used for Erichsen test. Punch speed is chosen as $18 \mathrm{~mm} / \mathrm{min}$ in DIN50102 standard. The speed range specified in the standard is 5$20 \mathrm{~mm} / \mathrm{min}$. With the punch touch to the sheet material, distance that until crack occurs in the material, gives the dome height (IE). In Fig. 6 is given schematically the Erichsen test method and die dimensions. The punch diameter is $20 \mathrm{~mm}$.

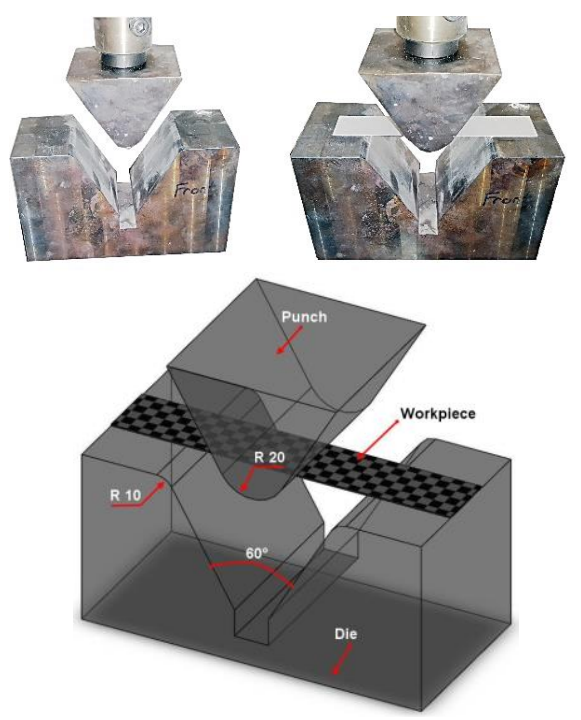

Fig. 5 A $60^{\circ} \mathrm{V}$-shaped bending test dimensions

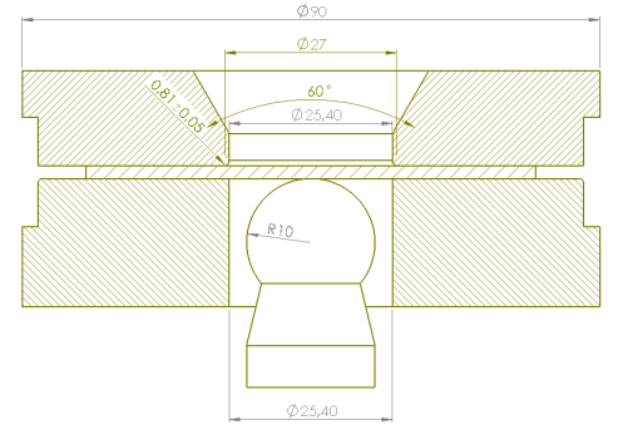

Fig. 6 Die dimensions of Erichsen test

\section{Result and discussion}

\subsection{Tensile test}

7075 aluminium alloy is a material that can be preferred in lightening instead of DP600 steel which is used extensively in the automotive industry. The yield strength of the DP600 steel is $355 \mathrm{MPa}$, and when the total strain is considered to be 0.2 , this condition is understood better [15]. It is shown that in both experiments at room temperature and $100^{\circ} \mathrm{C}$, the yield strength of the material increases with the increase of deformation rate. In the experiments performed at room temperature, while there is no significant change in the total strain deformation and tensile strength of the material, significant variations occur in the experiments performed at $100^{\circ} \mathrm{C}$ (Fig. 7). The tensile strength is expected to decrease as the yield strength increases with the increase in the deformation rate. However, there is no significant change in tensile strength.

In Fig. 8 is shown the true stress-strain curves of samples which are taken into solution at $500^{\circ} \mathrm{C}$ and then which are quenched at room temperature. In the experiments performed at room temperature, there is not much change in yield strength with deformation rate. In the tensile test device with thermal cabinet, the temperature is adjusted to $100^{\circ} \mathrm{C}$ and hot experiments are performed. Samples are kept at this temperature for 10 minutes and the experiment is started at the end of time. The effects of deformation speed are more pronounced in the experiments performed at $100^{\circ} \mathrm{C}$. At the same time, the yield and tensile strength of the material decreases due to the low aging. However, the 
test period is too long at $1 \mathrm{~mm} / \mathrm{min}$ and the tensile strength and the total elongation amount is higher, because the time of the aging time is too long. In Fig. 9 is given the change of tensile and yield strength with the deformation rate.

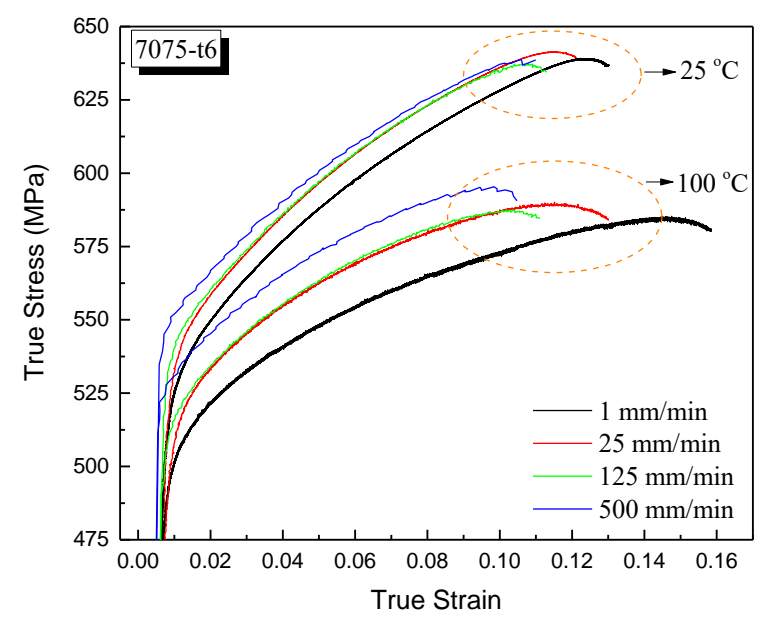

Fig. 7 The effect of different deformation rate and temperature for 7075-T6

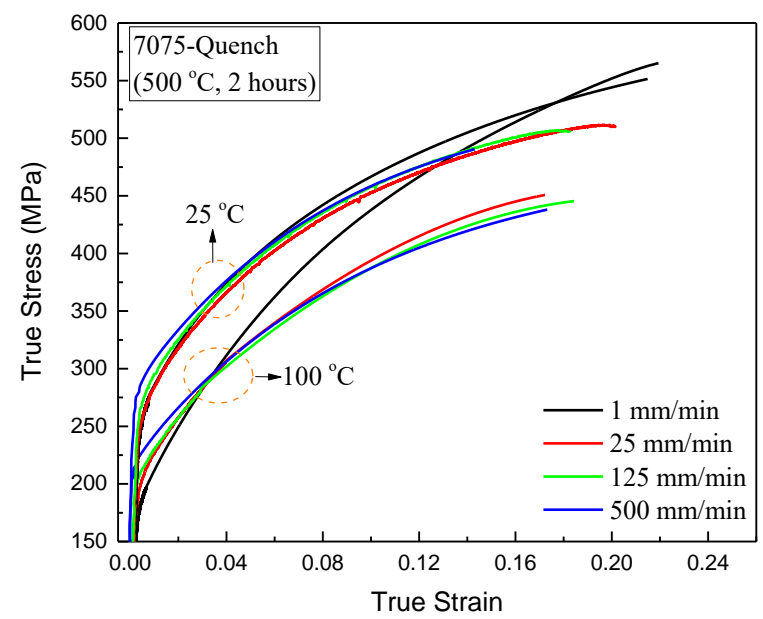

Fig. 8 The effect of different deformation rate and temperature for 7075-Quench

\subsection{Strain rate sensitivity $(\mathrm{m})$}

The strain rate sensitivity ratio $(\mathrm{m})$ is one of the factors affecting the beginning of the necking of the material. At the forming of the complex parts, all parts cannot be shaped at the same speed. Therefore, the response of the component to the strain rate ( $\mathrm{m}$ value) should be determined. With the positive value of $m$, the yield strength increases with deformation speed, and the negative $m$ value means that the yield strength will decrease with the increase of strain rate. In this study, $m$ values are investigated for two different situations. The $m$ value of the materials is generally determined by two different methods. The first method is to perform separate experiments at different speeds. The second is a jump test that gives more accurate results. In the jump test, two different strain rates are applied to the sample at the same time. The jump test results at 1 and $100 \mathrm{~mm} / \mathrm{min}$ strain rates are shown in Fig. 10.

The method of calculating the value of $m$ is shown in Fig. 11, a. The change of the true strain with strain rate sensitivity is given in Fig. 11, b. The strain rate sensitivity of the quench material is understood to be lower.
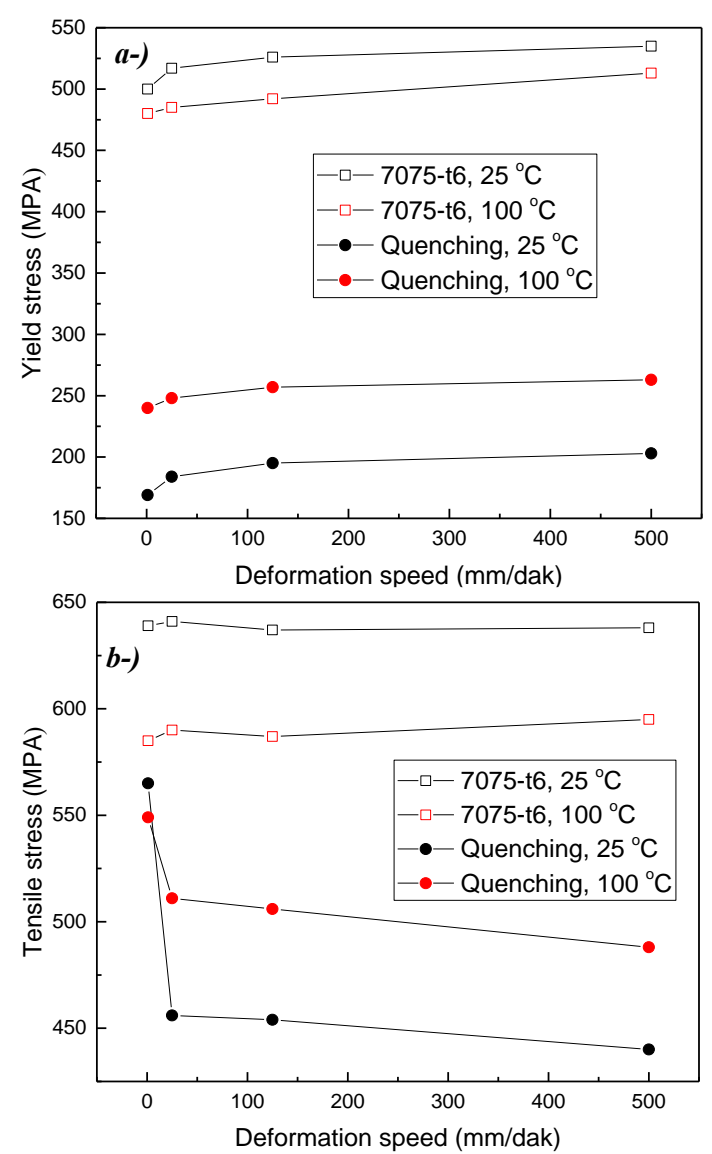

Fig. 9 Change of strength with deformation speed, a - yield strength, $\mathrm{b}$ - tensile strength

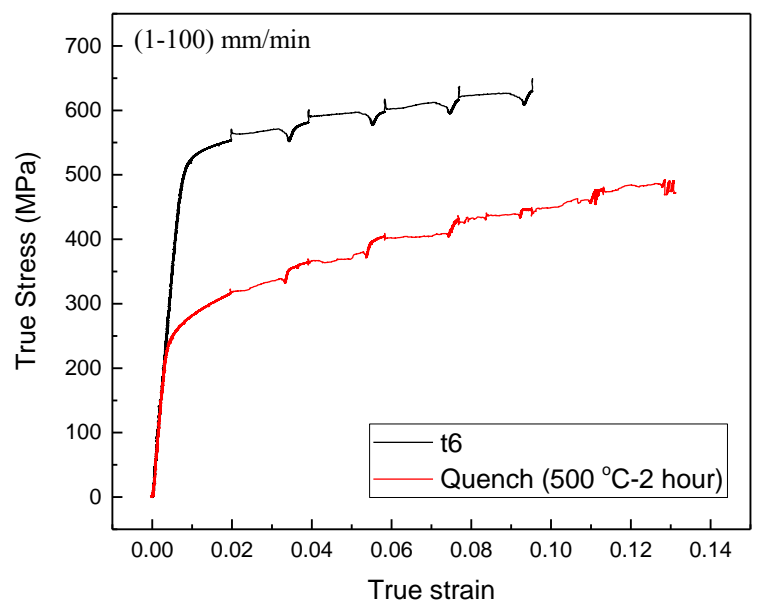

Fig. 10 Jump test results for different temperatures

\subsection{Springback}

Residual stresses occur due to plastic deformation when bending is applied to sheet metal. In the case of residual stresses, elastic recovery occurs when the punching force is eliminated in the shaped part. This phenomenon is called the springback. Particularly, it is more problematic in the assembled parts such as B pillar in automobiles. Factors such as punch radius, lubricant, punch speed, crushing force, dwell time, grain size, thickness are effective on springback [18-22]. Various strain rates are used for forming sheet metal. Strain rate is an important parameter because of the effect of hardening. Therefore, the effect of the punch speed should be known. 

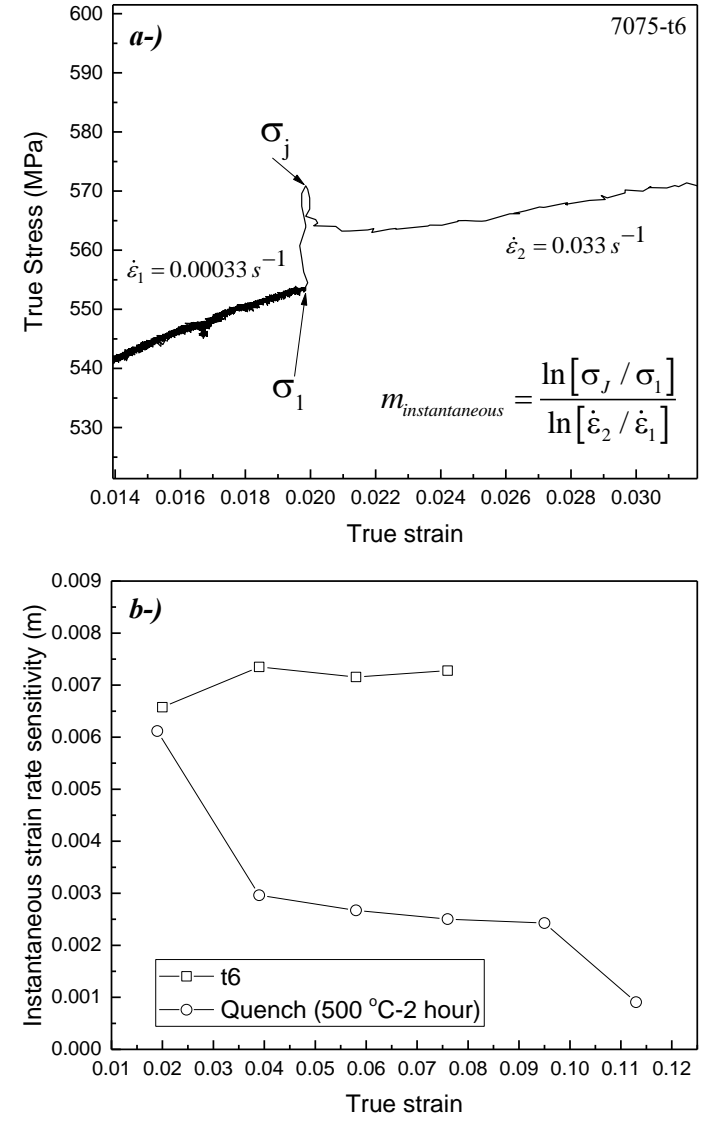

Fig. 11 a - Calculation of the jump test, b - Instantaneous strain rate sensitivity results

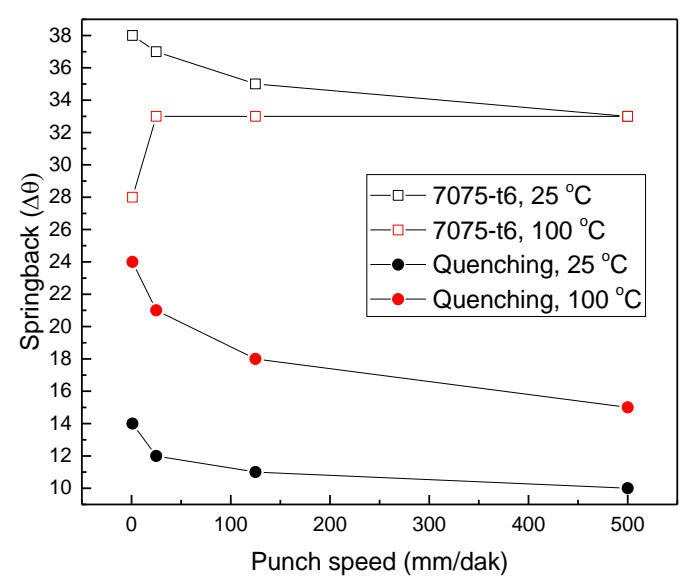

Fig. 12 Change of springback according to punch speed

As shown in Fig. 12, the springback amount of T6 tempering is $37^{\circ}$. With the increase of temperature and punch speed, the amount of springback decreases. This result is quite high for the automotive industry. For example, when you shape the DP600 steel at a $25 \mathrm{~mm} / \mathrm{min}$ punch speed at room temperature, $13.2^{\circ}$ springback occurs [15]. The biggest advantage of this material is the application of aging process. After the solution and quenching are applied to the material, if shaping is applied at room temperature, the amount of springback reduces $12^{\circ}$. Then, as a result of an artificial aging process, the strength of the material will be increased. Thus, aging process will be done in the process of paint baking.

In a study, examined the effect of punch speed on springback [23], bending is applied to SPCC and DP780 materials with the same thickness at different punch speeds between 0.07 and $70 \mathrm{~mm} / \mathrm{s}$. While at the SPCC material springback decreases with punch speed increase, DP780 is the opposite. In another study, it is shown that the increase of the punch speed at three different high-strength steel almost does not affect the springback in the bending process using the V-die [18]. Kiswanto et al. [19] performed a springback study on different parameters in the $\mathrm{V}$ bending die. They showed that with the increase of the punch speed, the amount of springback decreased. Chen investigated the effect of punch speed on three materials with different grain sizes [20]. While at some grain sizes punch speed does not change springback, at some grain sizes have been shown that punch speed decreases springback. Therefore, it is important to determine the springback behavior of each material.

\subsection{Erichsen test}

The Erichsen index is a simple method used to determine the formability of materials. The higher is the Erichsen index of a material, the better is its formability. In the case of a blank holder force of $6.5 \mathrm{kN}$ for T6, while the Erichsen index is $3.4 \mathrm{~mm}$, in the case of Quench it is $7.2 \mathrm{~mm}$ (Fig. 13). In short, its formability increases more than 2 times. The Erichsen index of DP600 steel in the same thickness is known to be around 5.5 [24]. The results, we found in our study are similar in the literature [6]. In addition, they also showed that the increase in temperature increases Erichsen index.

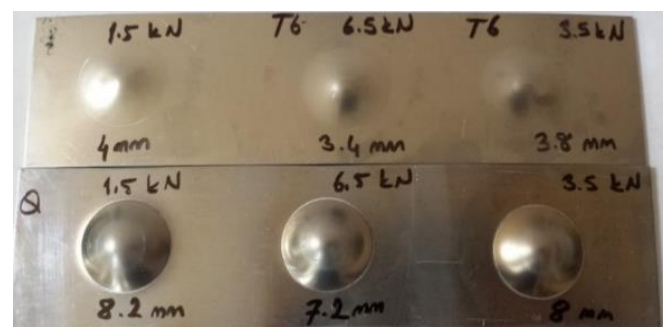

Fig. 13 Results of experimental Erichsen index

\subsection{Finite element analysis}

The trial and error method, which is common in the sheet metal industry, is gradually replaced by finite element analysis programs. The fact that the trial and error method is extremely laborious and is not costly suitable for the competitive environment of today. In the scope of this study, the springback process for 7075-T6 alloy is modelled in the finite element analysis program. DynaForm program is used in the modeling process. The results are compared by using both experimental and yield curve models in the material cards to be used in the analyzes. In order to investigate the effect of yield curve and yield criteria on the results, Hollomon, Krupskowsky yield curve models, and Barlat89, YLD2000 yield criteria are selected. These selected models include in all finite element analysis programs. In the material card is used these parameters; material density is $2.81 \mathrm{gr} / \mathrm{cm}^{3}$, Young modulus is $71.7 \mathrm{GPa}$, Poisson ratio is 0.33 , yield strengths are 523.5, 500.9, 530.1 and Lankford parameters are $0.38,0.69$ and $0.47(0,45,90$, respectively). Fully integrated shell element and 8 integration points are selected for springback analysis. High integration points in springback analysis are important for results. As in the experimental process, while the die is defined as constant, the 
punch speed is used as $25 \mathrm{~mm} / \mathrm{min}$. In the literature, it is stated in many studies that the model that best describes the material, should be chosen [25-27].

\subsubsection{Power law isotropic plasticity model}

Based on the isotropic hardening principle, this model has been developed for materials that exhibit elastoplastic behavior [28]. The most common equation is given in Eq. (1):

$$
\sigma_{y}=K(\varepsilon)^{n}
$$

where: $\sigma_{y}$ is yield stress, $K$ is strength coefficient, and $n$ is hardening exponential is expressed.

3.5.2. Strain rate sensitive power-law plasticity model

The effect of strain rate is included in the model [28]. The most general form is given in Eq. (2):

$$
\sigma=K(\varepsilon)^{n}(\dot{\varepsilon})^{m}
$$

where: $\sigma$ is yield strength, $\varepsilon$ is effective plastic strain, $\dot{\varepsilon}$ is effective plastic strain rate and $K, n, m$ are equation coefficients is expressed.

\subsubsection{Barlat's 3-parameter plasticity model}

The most general form of the equation is given in Eq. (3) [28]. Under the plane stress condition is based on the assumption that sheet materials will be shaped according to the anisotropy values:

$$
\begin{aligned}
& \sigma_{e f f}\left(\sigma_{11}, \sigma_{22}, \sigma_{12}\right)=\left(\frac{a}{2}\left|K_{1}+K_{2}\right|^{m}+\frac{a}{2}\left|K_{1}-K_{2}\right|^{m}+\right. \\
& \left.+\frac{c}{2}\left|2 K_{2}\right|\right)^{m \frac{1}{m}}, \\
& K_{1}=\frac{\sigma_{11}+h \sigma_{22}}{2}, K_{2}=\sqrt{\left(\frac{\sigma_{11}-h \sigma_{22}}{2}\right)^{2}+p^{2} \sigma_{12}^{2}},
\end{aligned}
$$

where: $a, c, p, h$ are determined by Lankford parameters. Detailed information is available in reference.

\subsubsection{Barlat_YLD2000 plasticity model}

The most general equation of this model developed according to the change of anisotropic properties of materials is given in Eq. (5). By making conversions between 610,8 equations with 8 unknowns are obtained and the coefficients obtained from this program are entered into the program.

$$
\begin{aligned}
& \Phi=\Phi^{\prime}+\Phi^{\prime \prime}=2 \sigma^{a}, \\
& \Phi^{\prime}=\left|S_{1}+S_{2}\right|^{a}, \Phi^{\prime \prime}=\left|2 S_{2}+S_{1}\right|^{a}+\left|2 S_{1}+S_{2}\right|^{a},
\end{aligned}
$$

$$
\begin{aligned}
& \Phi=\Phi^{\prime}\left(X^{\prime}\right)+\Phi^{\prime \prime}\left(X^{\prime \prime}\right)=2 \sigma^{a}, \\
& \Phi^{\prime}=\left|X_{1}^{\prime}+X_{2}^{\prime}\right|^{a}, \Phi^{\prime \prime}=\left|2 X_{2}^{\prime \prime}+X_{1}^{\prime \prime}\right|^{a}+\left|2 X_{1}^{\prime \prime}+X_{2}^{\prime \prime}\right|^{a}, \\
& X^{\prime}=C^{\prime} s=C^{\prime} T \sigma=L^{\prime} \sigma \\
& X^{\prime \prime}=C^{\prime \prime} s=C^{\prime \prime} T \sigma=L^{\prime \prime} \sigma
\end{aligned}
$$

$\left[\begin{array}{l}L_{11}^{\prime} \\ L_{12}^{\prime} \\ L_{21}^{\prime} \\ L_{22}^{\prime} \\ L_{66}^{\prime}\end{array}\right]=\left|\begin{array}{ccc}2 / 3 & 0 & 0 \\ -1 / 3 & 0 & 0 \\ 0 & -1 / 3 & 0 \\ 0 & 2 / 3 & 0 \\ 0 & 0 & 1\end{array}\right|\left|\begin{array}{l}\alpha_{1} \\ \alpha_{2} \\ \alpha_{7}\end{array}\right|$,

$$
\left[\begin{array}{l}
L_{11}^{\prime \prime} \\
L_{12}^{\prime \prime} \\
L_{21}^{\prime \prime} \\
L_{22}^{\prime \prime} \\
L_{66}^{\prime \prime}
\end{array}\right]=\frac{1}{9}\left|\begin{array}{ccccc}
-2 & 2 & 8 & -2 & 0 \\
1 & -4 & -4 & 4 & 0 \\
4 & -4 & -4 & 1 & 0 \\
-2 & 8 & 2 & -2 & 0 \\
0 & 0 & 0 & 0 & 9
\end{array}\right|\left|\begin{array}{c}
\alpha_{3} \\
\alpha_{4} \\
\alpha_{5} \\
\alpha_{6} \\
\alpha_{8}
\end{array}\right| .
$$

Eqs. (11) and (12) are used as yield curve models $\left(25^{\circ} \mathrm{C}, 25 \mathrm{~mm} / \mathrm{min}\right.$ for $\left.\mathrm{T} 6\right)$.

$$
\text { Hollomon } \sigma(h)=K\left(\varepsilon^{p}\right)^{n} \text {, }
$$

$$
\text { Krupskowky } \sigma(h)=K\left(\varepsilon_{0}+\varepsilon^{p}\right)^{n} \text {. }
$$

Model coefficients are obtained by using curve fitting method and in Table 2 is given. In Fig. 14 is shown the experimental yield curve with model estimates.

Table 2

Yield curve model parameters

\begin{tabular}{|l|l|l|l|l|}
\hline & $K(\mathrm{MPa})$ & $n$ & $\varepsilon_{0}$ & $R^{2}$ \\
\hline Hollomon & 760.873 & 0.079 & - & 0.993 \\
\hline Krupskowsky & 783.95 & 0.093 & 0.0056 & 0.997 \\
\hline
\end{tabular}

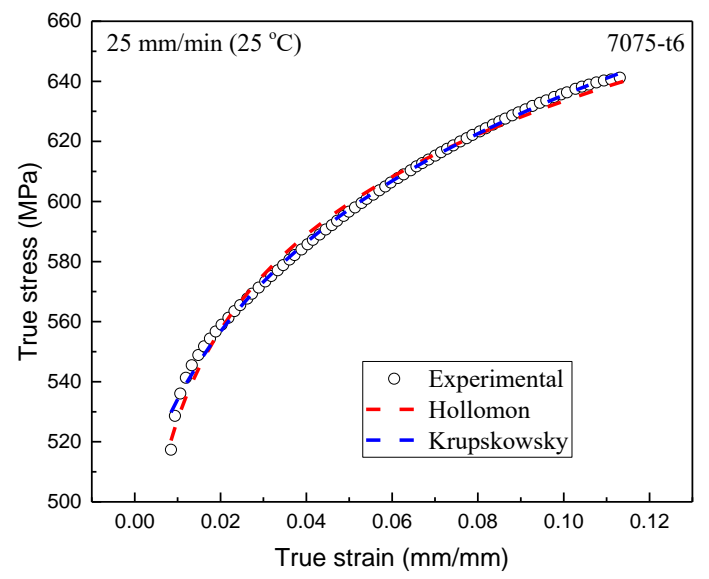

Fig. 14 Flow curve model results for T6

Among the yield criteria used, it is observed that the Barlat_YLD2000 yield criterion gives the closest estimate. Experimental values are used in this analysis. If the model parameters in Table 2. are used, the predicted springback varies. Therefore, the selected yield curve model should best describe the material. In Fig. 16 is shown the analysis results of the Barlat model with 3 parameters and 
Barlat_YLD2000 yield criteria. The variation of the stress distributions on the material varies in each model.

Wang et all. made $\mathrm{U}$ and $\mathrm{L}$ bending in the AA5754 alloy and they modelled the springback process [29]. They show that the results of the analysis are consistent with the experimental results.

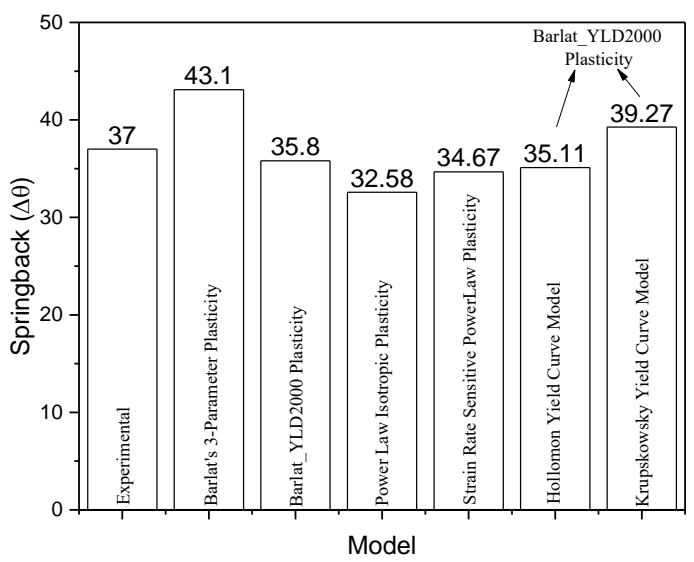

Fig. 15 Finite element analysis results

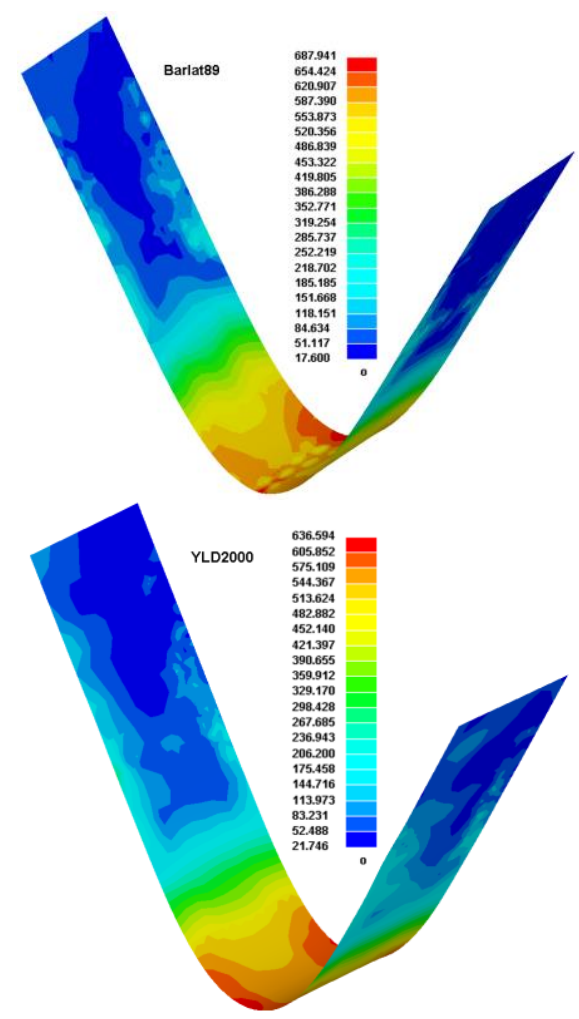

Fig. 16 Results of yield criteria

\section{Conclusions}

Recently for lightening study, 7XXX series aluminium alloys, which are widely used in the aerospace industry, also are investigated in the automotive industry. This interest is increasing due to their high strength and aging. Studies are being carried out to investigate the formability of this material, which has poor formability at room temperature. In this study, the effect of different deformation rates, temperature and heat treatment are investigated. As a result of the investigations, it is observed that the formability increases after quenching. By using the paint baking process in the automotive industry, the strength of the material can also be increased. In addition, by using the experimental data obtained, the bending process is modelled and springback estimates are examined. It is shown that the Barlat_YLD2000 yield criterion is successful and that the results change according to the selected yield curve model.

\section{Acknowledgements}

The analyzes in this study were carried out at Niğde Ömer Halisdemir University.

\section{References}

1. Nam, J. B. 2013. Development of new auto steels and application technology [cited 01.01.2016; Available from Internet:

http://309fbf2c62e8221fbaf0-

b80c17cbaf20104b072d586b316c6210.r88.cf1.rackcdn. com/Gangzhao\%20Presentations/09_China\%20Autom otive\%20Steel\%20Conference_POSCO_JaeBok\%20Nam.pdf.

2. Altan, T.; Long, J. 2015. Forming aluminum alloys at elevated temperatures, Part 1, How process details change for warm and hot forming, Stamping Journal 1.

3. Ekvall, J.; Rhodes, J.; Wald, G. 1982. Methodology for evaluating weight savings from basic material properties, in Design of Fatigue and Fracture Resistant Structures, STP28867S, P. Abelkis and C. Hudson, Editors., ASTM International: West Conshohocken, PA. p. 328-341.

4. Behrens, B. A.; Hübner, S.; Vogt, H. 2018. Formability of 7000 aluminum alloys in warm and hot forming condition, IOP Conference Series: Materials Science and Engineering, 418(1). https://doi.org/10.1088/1757-899X/418/1/012027.

5. Behrens, B. A.; Nürnberger, F.; Bonk, C.; Hübner, S.; Behrens, S.; Vogt, H. 2017. Influences on the formability and mechanical properties of 7000aluminum alloys in hot and warm forming, Journal of Physics: Conference Series 896(1).

https://doi.org/10.1088/1742-6596/896/1/012004.

6. Huo, W.; Hou, L.; Zhang, Y.; Zhang, J. 2016. Warm formability and post-forming microstructure/property of high-strength AA 7075-T6 Al alloy, Materials Science and Engineering: A, 675 .

https://doi.org/10.1016/j.msea.2016.08.054.

7. Kumar, M. 2017. AW-7075-T6 sheet for shock heat treatment forming process. Transactions of Nonferrous Metals Society of China, 27(10). https://doi.org/10.1016/S1003-6326(17)60241-3.

8. Feister, T.; Kim, H.; Gwinn, A.; Schiller, T.; Austin, M. 2018. Failure predictions in warm forming of 7075T6 aluminum structural parts, IOP Conference Series: Materials Science and Engineering 418(012024). https://doi.org/10.1088/1757-899X/418/1/012024.

9. Xiao, W.-C.; Wang, B.-Y.; Kang, Y.; Ma, W.-P.; Tang, X.-F. 2017. Deep drawing of aluminum alloy 7075 using hot stamping, Rare Metals, 36(6). https://doi.org/10.1007/s12598-017-0919-4.

10. Liu, Q.; Chen, S.; Gu, R.; Wang, W.; Wei, X. 2018. Effect of Heat Treatment Conditions on Mechanical Properties and Precipitates in Sheet Metal Hot Stamping of 7075 Aluminum Alloy, Journal of Materials Engineering and Performance, 27(9). https://doi.org/10.1007/s11665-018-3588-z. 
11. Polak, S.; Kaczyński, P.; Gronostajski, Z.; Jaskiewicz, K.; Krawczyk, J.; Skwarski, M.; Zwierzchowski, M.; Chorzępa, W. 2017. Warm forming of 7075 aluminum alloys, Procedia Engineering, 207. https://doi.org/10.1016/j.proeng.2017.10.1015.

12. Liu, Y.; Zhu, Z.; Wang, Z.; Zhu, B.; Wang, Y.; Zhang, Y. 2017. Formability and lubrication of a Bpillar in hot stamping with 6061 and 7075 aluminum alloy sheets, Procedia Engineering, 207. https://doi.org/10.1016/j.proeng.2017.10.819.

13. Jang, D. H.; Kim, W. J. 2018. Warm Temperature Deformation Behavior and Processing Maps of 5182 and 7075 Aluminum Alloy Sheets with Fine Grains, Metals and Materials International 24(3). https://doi.org/10.1007/s12540-018-0061-3.

14. Özdemir, M.; Gökmeșe, H. 2018. Microstructural Characterization and Deformation of X10CrAlSi24 Sheet Material Applied V-Bending Process, Tehnički vjesnik 25(3). https://doi.org/10.17559/TV-20170425022545.

15. Kilic, S.; Ozturk, F. 2016. Comparison of performances of commercial TWIP900 and DP600 advanced high strength steels in automotive industry, Journal of the Faculty of Engineering and Architecture of Gazi University 31(3). https://dx.doi.org/10.17341/gummfd.81389.

16. Kilic, S.; Ozturk, F.; Sigirtmac, T.; Tekin, G. 2015. Effects of Pre-strain and Temperature on Bake Hardening of TWIP900CR Steel. Journal of Iron and Steel Research, International 22(4). https://doi.org/10.1016/S1006-706X(15)30012-1.

17. Sáenz de Argandoña, E.; Galdos, L.; Ortubay, R.; Mendiguren, J.; Agirretxe, X. 2015. Room temperature forming of AA7075 aluminum alloys: Wtemper process, Key Engineering Materials 651-653. https://doi.org/10.4028/www.scientific.net/KEM.651653.199 ,

18. Fu, X. J.; Li, J. J.; Xu, G. 2011. Experimental study on springback of high strength sheet metals, Materials Research Innovations 15(sup1). https://doi.org/10.1179/143307511X12858957675912

19. Kiswanto, G.; Mahmudah, A.; Priadi, D. 2017. Preliminary investigation of micro-V-bending, MATEC Web Conf. 108. https://doi.org/10.1051/matecconf/201710806001.

20. Chen, C. C. 2014. Experimental study on punch radius and grain size effects in V-bending process, Materials and Manufacturing Processes 29(4). https://doi.org/10.1080/10426914.2014.880468.

21. Wan-Nawang, W. A.; Qin, Y.; Liu, X. 2015. An experimental study on the springback in bending of $\mathrm{W}$ shaped micro sheet-metal parts, MATEC Web of Conferences 21. https://doi.org/10.1051/matecconf/20152109015.

22. Pritima, D.; Padmanabhan, P. 2018. Investigation of sheet bending parameters on springback in nickel coated mild steel sheets using response surface methodology, Mechanics \& Industry 19(2).

https://doi.org/10.1051/meca/2018009.

23. Choi, M.K.; Huh, H. 2014. Effect of punch speed on amount of springback in U-bending process of autobody steel aheets, Procedia Engineering 81. https://doi.org/10.1016/j.proeng.2014.10.125.
24. Song, Y.; Hua, L. 2014. Influences of thickness ratio of base sheets on formability of tailor welded blanks, Procedia Engineering 81.

https://doi.org/10.1016/j.proeng.2014.10.068.

25. Peng, X.; Shi, S.; Hu, K. 2013. Comparison of material models for spring back prediction in an automotive panel using finite element method, Journal of Materials Engineering and Performance 22(10). https://doi.org/10.1007/s11665-013-0600-5.

26. Firat, M.; Kaftanoglu, B.; Eser, O. 2008. Sheet metal forming analyses with an emphasis on the springback deformation, Journal of Materials Processing Technology 196(1). https://doi.org/10.1016/j.jmatprotec.2007.05.029.

27. Eggertsen, P. A.; Mattiasson, K. 2010. On constitutive modeling for springback analysis, International Journal of Mechanical Sciences 52(6). https://doi.org/10.1016/j.ijmecsci.2010.01.008.

28. LS-DYNA. 2018. LS-DYNA Theory Manual. 2018 [cited 2018; Available from Internet:

http://www.lstc.com/dynamat/pdfs/mat_018_theory.pdf

29. Wang, A.; Zhong, K.; El Fakir, O.; Liu, J.; Sun, C.; Wang, L.-L.; Lin, J.; Dean, T.A. 2017. Springback analysis of AA5754 after hot stamping: experiments and FE modelling, The International Journal of Advanced Manufacturing Technology 89(5). https://doi.org/10.1007/s00170-016-9166-3

\section{S. Kilic}

EXPERIMENTAL AND NUMERICAL INVESTIGATION OF THE EFFECT OF DIFFERENT TEMPERATURE AND DEFORMATION SPEEDS ON MECHANICAL PROPERTIES AND SPRINGBACK BEHAVIOUR IN AL-ZN-MG-CU ALLOY

S u m m a r y

Thanks to their low density and high strength, the 7XXX series aluminum alloys are widely used as a support/beam parts in the aerospace industry. This alloy is target in the lightening studies of the automotive industry and surveys for sheet metal are still in progress. It is a series of alloys that can be applied to the aging process and has the most effect on mechanical properties. As formability is quite weak, methods are investigated. In this study, tensile test, bending test and Erichsen tests are performed at different deformation rates and temperatures. As a result of the experiments, it has been seen that the formability increases at high temperature and low deformation rates. If paint baking time is long, there will be no loss of strength. Also, the bending process is modeled with the help of the finite element analysis programs and the springback estimations are examined. It is seen that the results of the modeling process are quite successful. The effect of the strain rate sensitivity is determined.

Keywords: 7XXX; AA7075; bending; Erichsen; springback; sheet metal forming.

Received February 04, 2019

Accepted October 14, 2019 